REVISTA DE DERECHO UNED, NÚM. 13, 2013

\title{
DIGNIDAD Y LIBRE DESARROLLO DE LA PERSONALIDAD EN MENORES: DAÑOS EN EL ÁMBITO DE LAS NUEVAS TECNOLOGÍAS DE LA INFORMACIÓN
}

\section{DIGNITY AND FREE DEVELOPMENT OF THE PERSONALITY IN CHILDREN: DAMAGE IN THE FIELD OF NEW INFORMATION TECHNOLOGIES.}

\section{FRANCISCO SACRISTÁN ROMERO}

Licenciado en Derecho. (Doctorando UNED)

Resumen: La irrupción masiva de las nuevas tecnologías de la información y comunicación han proyectado consecuencias jurídicas de primer orden en el ámbito turístico, especialmente en el turismo sexual, y en un segundo término en el denominado turismo de ferias y congresos que, en numerosas ocasiones, aparece vinculado al primero en concentraciones y eventos multitudinarios que se celebran en las grandes ciudades del planeta. La aparición del escenario virtual que conforma el ciberespacio ha afectado y afecta, sobre todo, a una minoría bastante desprotegida como son los menores en su rol de víctimas de las modalidades de explotación del siglo XXI.

Abstract: The massive emergence of new information and communication technologies have been projected legal consequences of first order in the tourism field, especially in sex tourism, and a second in the so-called tourism fairs and congresses that, on numerous occasions, it appears linked to the first in concentrations and multitudinous events that are held in big cities on the planet. The emergence of the virtual scenario that makes up cyberspace has affected and affects, above all, a fairly unprotected minority as they 
are minors in their role as victims of the modes of exploitation of the 21st century.

Palabras claves: Derechos fundamentales, Dignidad, menores, nuevas tecnologías, turismo.

Key words: Fundamental rights, dignity, minors, new technologies, tourism.

Recepción original: 17/09/2013

Aceptación original: 30/09/2013

Sumario: I. Reflexiones previas sobre la dignidad de la persona. II. Factores internos y externos vinculados a la dignidad del menor y libre desarrollo de su personalidad. III. Las connotaciones del turismo sexual en la personalidad del menor. IV. Conclusiones. Bibliografía.

\section{REFLEXIONES PREVIAS SOBRE LA DIGNIDAD DE LA PERSONA}

A partir de lo establecido en su artículo 10 por la Constitución Española de 1978 (en adelante denominada con las siglas CE), titulado "Derechos de la persona», se tratarán a continuación, en las siguientes líneas, vinculadas a la dignidad de la persona y libre desarrollo de la personalidad, diversas características nucleares que conectan directamente con el objeto de este artículo, en el sentido de la afectación que, sobre los menores, tienen la acción y los usos perjudiciales del turismo, en una época como la actual, en que la introducción y utilización masiva de las nuevas tecnologías de la información y comunicación, a través de sus múltiples soportes y canales (en general, se empleará para su identificación el acrónimo anglosajón internacionalmente estandarizado y normalizado de TIC), han facilitado que se cometan con más frecuencia y si cabe podría añadir con más violencia (porque a la física de todos los tiempos se añade la virtual o a distancia mediada técnicamente y de carácter más psíquico o psicológico pero con derivaciones somáticas que pueden finalizar en efectos muy graves para la salud integral de niñas y niños), vulneraciones muy virulentas y desde cualquier parte del mundo donde se disponga de una conexión con cierta capacidad y velocidad mínima de acceso a Internet u a otro tipo de redes telemáticas de transmisión instantánea de datos, voz y la múltiple tipología de recursos audiovisuales contra la propia integridad física y moral de la persona por el trascendental hecho de ser persona. Para ello, se 
seguirá lo que significan los «derechos fundamentales» desde su tratamiento material, siguiendo a Álvarez Conde (1991: 14) ${ }^{1}$, con estos dos requisitos:

a) La estipulación como «derechos subjetivos» de la ciudadanía en su relación con los poderes públicos con el objetivo del aseguramiento de «un status jurídico de libertad de la persona».

b) Objetivación de los derechos fundamentales como elementos orientadores de la convivencia de la sociedad en un Estado democrático y plural como el español.

Ambos aspectos no solucionan el problema apuntado también en otro trabajo posterior por Álvarez Conde $(2004: 116)^{2}$ como una carencia de la $\mathrm{CE}$ en cuanto a la inexistencia de una exacta definición de lo que debe entenderse por «derechos fundamentales» previa a la enumeración de los mismos que se realiza en el Título I.

La dignidad de la persona es el primero de los derechos que se enumera en el artículo 10 de la CE, apartado 1. Para acotar los problemas que entraña este concepto respecto a la temática planteada, es pertinente traer el pensamiento de Torres del Moral (1992: 19-20) ${ }^{3}$, en lo que concierne al mayor «contenido axiológico» de la constitucionalización de la dignidad, si se compara con otros valores superiores del ordenamiento jurídico español, como es el caso, para este autor, del pluralismo político, lo que implicaría su configuración como un valor superior más y su exclusión del artículo 10.1 de la CE.

A continuación, la tarea se centrará en tratar de identificar sus elementos más básicos que se pueden percibir implicados, para un mejor apoyo en la defensa de los derechos fundamentales del menor, cuando coinciden en tiempo y lugar, prácticas en torno a fenómenos relacionados con el turismo sexual, y en los últimos años como un apéndice o modalidad de éste, el denominado turismo de ferias y congresos que, en las grandes ciudades de los países occidentales e incluso otros con menor índice de desarrollo, genera la concentración masiva alrededor de una serie de actos y eventos de todo tipo, de individuos interesados a partir de la información previa que reciben por las plataformas tecnológicas cualesquiera que sea su punto

\footnotetext{
1 ÁlVAREZ CONDE, E., «Algunos aspectos del régimen jurídico de la prensa», Revista de derecho político, 34, 1991, pp. 11-70.

2 ÁLVAREZ CONDE, E., "El sistema constitucional español de derechos fundamentales», Corts: Anuario de derecho parlamentario, (Ejemplar dedicado a: XXV aniversario de la Constitución Española), 15, 2004, pp. 115-146.

3 TORRES DEL MORAL, A., "Valores y principios constitucionales», Revista de derecho político, 36, 1992, pp. 17-26.
} 
de acceso, a los denominados de modo eufemístico «servicios», ofrecidos por las organizaciones criminales y mafiosas de trata y explotación sexual de niñas y niños, para obtener, en última instancia, como primer objetivo, altas ganancias económicas y en segundo lugar, connotaciones de poder estratégico entre bandas similares ${ }^{4}$.

Una de las primeras reflexiones importantes es preguntarse si la dignidad como tal puede ser considerada como un derecho fundamental o, por el contrario, su categorización debe vehicularse como un principio general con nítidas concreciones axiológicas en la línea antes apuntada por Torres del Moral (1992: 19-20) ${ }^{5}$ que puedan encontrarse en los textos constitucionales, teniendo presente las indudables vinculaciones para el objeto de estudio por la cierta "desnaturalización» que ha emergido en el mundo de los valores universales de la persona en pleno siglo XXI debido a las cada vez más frecuentes prácticas delictivas que se apoyan en las nuevas tecnologías de la información y comunicación cuando se emplean como medio para explotar sexualmente a seres humanos indefensos como los menores en destinos turísticos. Clara demostración de la anterior disyuntiva es que en la propia $\mathrm{CE}$ se encuentra fuera del conjunto de derechos fundamentales y libertades públicas que disfrutan de una mayor protección jurídica a través del recurso de amparo, hecho que ha motivado que se discuta si debe considerarse a la dignidad como un valor o regla común frente a su concepción como derecho fundamental en sentido estricto de la acepción (Batista, 2006: 3) ${ }^{6}$.

Desde el enfoque que se pretende ofrecer en esta tesis doctoral, no debe ignorarse que los planteamientos iniciales en esta parte general serían diferentes si la dignidad formara parte de los derechos fundamentales y libertades públicas que se recogen en el Título I de la CE por cuanto gozaría de unas mayores garantías jurídicas si se piensa en los acontecimientos que sobre todo atentan contra la

4 Un ejemplo práctico y bien elocuente es la comprobación que se puede realizar en los alrededores de las inmediaciones de cualquier recinto ferial, como puede ser IFEMA en Madrid, acerca de la sistemática e innumerable «invasión» de folletos publicitarios que pretenden atraer la atención de visitantes mayoritariamente de sexo masculino hacia los focos de prostitución femenina infantil concentrados en locales de las periferias de las urbes y que antes de ser ofrecidos en soporte papel de buena calidad son anunciados hasta en sus detalles más insignificantes con toda clase de despliegue de los recursos más innovadores tecnológicamente en Internet y en otros medios de recepción y transmisión instantánea de datos como aparatos de telefonía personal, agendas electrónicas, y un largo etcétera que de manera permanente se van renovando en el mercado doméstico y personal de la informática y las comunicaciones.

5 Ob. cit.

6 BATISTA JIMÉNEZ, F., «La dignidad de la persona en la Constitución española: naturaleza jurídica y funciones», Cuestiones Constitucionales, 14, 2006, pp. 3-20. 
propia dignidad de la persona como aquellos a los que deben enfrentarse los menores que se ven envueltos contra su propia voluntad en organizaciones criminales que les utilizan con fines lucrativos en el ámbito turístico.

En segundo lugar, constatar la existencia de un sector doctrinal que entiende la dignidad conectada con la plena integridad física y moral del individuo e ineludiblemente unida a valores esenciales como, entre otros, paz, justicia, libertad, etcétera, que en esta segunda vertiente conectaría con la teoría ya manifestada por Torres del Moral sobre el mayor "contenido axiológico» de este principio recogido en el artículo 10.1 de la CE respecto a otros valores superiores del ordenamiento jurídico español:

«Estos pilares de nuestra sana y humana convivencia, están conformados por el orden, la paz, el bien común, libertad, justicia y defensa de la Nación. Para que estos principios guarden vigencia y operatividad, deben orientarse todas las decisiones jurídicas y políticas, entre otras, a mantener las normas constitucionales que tutelen la dignidad de la persona humana en su integridad física y moral» (Robledo, 2008: 266) ${ }^{7}$.

Guillén (2009: 153) ${ }^{8}$ sitúa a la dignidad como origen a partir del cual tienen lugar los derechos fundamentales en el marco territorial europeo, otorgando a la misma una función crucial en el proceso de elaboración de los textos constitucionales en los Estados que se proclaman en el viejo continente como democráticos, sociales y de Derecho:

«Europa es hoy la nueva e inexorable realidad; una realidad compleja desde el punto de vista jurídico. Es una comunidad constitucional en desarrollo a partir esencialmente de dos organizaciones: el Consejo de Europa y la Unión Europea. El primero supuso históricamente el primer jalón: la cooperación a través de los derechos que ha hecho posible una aproximación sustancial de las tradiciones jurídicas en la medida en que los ordenamientos europeos parten en su acepción actual de la democracia constitucional y del juego atribuido en ésta a los derechos fundamentales como emanaciones del concepto de dignidad humana».

\footnotetext{
7 ROBLEDO, F. J., "Las reformas constitucionales provinciales deben preservar el derecho a la dignidad de la persona humana en su integridad psicofísica», Estudios constitucionales: Revista del Centro de Estudios Constitucionales, 1, 2008, pp. 265-279.

GUILLÉN LÓPEZ, E., «Metodología del Derecho Constitucional Europeo. Un derecho Constitucional para la integración política de Europa. Del pluralismo ideológico», Revista de derecho constitucional europeo, 12, 2009, pp. 151-170.
} 
En un tercer orden, algunos principios que García Couso y Álvarez Conde (2001: 181) ${ }^{9}$ mantienen como esenciales del sistema constitucionalista en España deben tenerse en cuenta en estas líneas tanto en cuanto son inherentes al propio derecho personal a la dignidad en menores: «igualdad, proporcionalidad y razonabilidad», siendo todos ellos ejes esenciales de argumentación en este trabajo de investigación a lo largo de sus diferentes partes.

Otro aspecto interesante es el que ilustra Oehling $(2011)^{10}$ en cuanto a la introducción y adopción del concepto «dignidad» en la tradición democrática occidental a través de dos vías: por un lado, su incorporación directa como un precepto más dentro de los textos constitucionales en Alemania (1949), Hungría (1990) ${ }^{11}$ y Polonia (1997) ${ }^{12}$, así como la CE de 1978 o, por el contrario, su entrada en el ordenamiento jurídico a través de la jurisprudencia emanada de los Tribunales Constitucionales, con el ejemplo de Suiza. Todo esto implica la importancia que el recorrido histórico de las sociedades despliega para una mayor vertebración de los derechos fundamentales en los textos constitucionales del pasado siglo XX, como apunta José María Cayetano Núñez Rivero (2010: 701) ${ }^{13}$ en la reseña que realiza de la obra de José Manuel Vera Santos $(2008)^{14}$ titulada «Las Constituciones de España».

A Oehling $(2011)^{15}$, el modo de introducción directa como un artículo de referencia en la Constitución del país que se trate, a diferencia de la opción jurisprudencial, le parece que ofrece mayores garantías a la ciudadanía en cuanto a la consideración de derecho «positivizado» en la norma suprema. Es partidario que la dignidad

9 GARCÍA COUSO, S; ÁLVAREZ CONDE, E., «La barrera electoral», Revista de derecho político, 52, 2001, pp. 177-204.

10 OEHLING DE LOS REYES, A., «El concepto constitucional de dignidad de la persona: forma de comprensión y modelos predominantes de recepción en la Europa continental囚, Revista española de derecho constitucional, 31, 2011, pp. 135-178.

11 En lo que se refiere a Hungría hay que advertir que su Constitución de 1990, resultado de la desmembración de la antigua y desaparecida Unión Soviética y la caída del Muro de Berlín en 1989, ha realizado un tratamiento de la dignidad muy similar a lo previamente estipulado en Alemania en 1949 con la Ley Fundamental de Bonn y la CE de 1978, aunque con singularidades propias y específicas no extrapolables a otros textos constitucionales del entorno de la Unión Europea de la que es miembro de pleno derecho.

12 Lo mismo anterior de Hungría cabe afirmar del caso de Polonia, cuya actual Constitución tiene vigencia desde 1997.

13 CAYETANO NÚÑEZ RIVERO, J. M., «VERA SANTOS, José Manuel: Las Constituciones de España», Teoría y realidad constitucional, 25, 2010, pp. 695-702.

14 VERA SANTOS, J.M., Las Constituciones de España, Navarra, ThomsonCivitas, 2008.

15 Ob.cit. 
quede reflejada de manera inmediata en los textos constitucionales de forma expresa en un precepto concreto, quedando postergada su adopción en los ordenamientos jurídicos por la vía jurisprudencial a través de los Tribunales Constitucionales o similares como segundo recurso y, por extensión, considerado secundario.

Por su parte, Nuevo $(2004)^{16}$, circunscribiendo su análisis a la CE de 1978, entronca la dignidad con los cuatro valores superiores del texto constitucional español, aunque a lo que a protección de menores en el marco turístico se refiere interesa especialmente lo relacionado con justicia, igualdad y libertad, dejando aparte el pluralismo político que no es significativo a los efectos del objeto de estudio. Sobre todo relevante y que será focalizada con un tratamiento específico posterior en otra parte de este trabajo parece la justicia si se concentra la atención en la seguridad jurídica como principio general, por cuanto el empleo de las nuevas tecnologías en las actuales circunstancias lleva a que el turismo sexual cada vez más afecte a menores que incluso provienen de familias de clase social media y no solamente sea el reflejo de atraer a niñas y niños que crecen y viven con escasez en cuanto a sus condiciones económicas y materiales en los países subdesarrollados y que en muchas ocasiones no han utilizado ni conocen un equipo informático en sus prestaciones más básicas.

Landa $(2002)^{17}$, criticando de manera constructiva lo que se plasma en la CE de 1978 respecto a la no consideración de la dignidad como un derecho fundamental con las mayores garantías jurídicas, se decanta por inclinarse favorable a una corriente de opinión que defiende que la dignidad debería ser incluso el primer derecho fundamental por delante de los que se han recogido como tales por el texto constitucional español en el Título I, quizás más influido por percepciones con raíz filosófica en torno a la dignidad que aquellas otras de índole jurídica.

Hoyos (1994) $)^{18}$ manifiesta que la dignidad debe erigirse en el núcleo esencial de los derechos fundamentales del ser humano desde el cual se conformen el resto. A diferencia de Landa $(2002)^{19}$ sí parece

16 NUEVO, P., «Pluralismo y bien común en el Derecho Constitucional囚, Díkaion: revista de actualidad jurídica, 13, 2004.

17 LANDA, C., «Dignidad de la persona humana», Cuestiones constitucionales: revista mexicana de derecho constitucional, 7, 2002, pp. 110-138.

18 HOYOS, I.M., "El respeto a la dignidad de la persona y los Derechos Humanos en la Constitución política de Colombia», Díkaion: revista de actualidad jurídica, 3, 1994, pp. 26-51.

19 Ob.cit. 
existir en esta autora una perspectiva más propiamente jurídica que la filosófica planteada por el anterior.

Benda (2001: 117-118) ${ }^{20}$, realzando la importancia de la dignidad en las Constituciones, introduce un elemento de debate interesante en cuanto a la fundamentación religiosa de este derecho personal, enfatizando su origen histórico en el cristianismo:

«Frente a la optimista presunción de que en Occidente imperó desde tiempos inmemoriales una creencia en los derechos fundamentales, cabe hacer toda una serie de objeciones. Históricamente, la garantía de la dignidad humana se encuentra estrechamente ligada al cristianismo. Su fundamento radica en el hecho de que el hombre ha sido creado a imagen y semejanza de Dios».

Este autor realiza una defensa de la dignidad desde la perspectiva manifestada que en algunos textos constitucionales, que parte de la doctrina han entendido adelantados al momento de su entrada en vigor (y un claro ejemplo es la CE de 1978), no se haya equiparado al resto de derechos fundamentales que tienen un mayor blindaje jurídico como sí existe en la Ley Fundamental de Bonn:

«La dignidad de la persona está protegida no sólo por el art. 1 GG, sino también por sus arts. 2 y ss. GG, con orientación en cada caso a las posibilidades concretas de amenaza. Común a todos los derechos fundamentales es que parezcan necesarios para la dignidad de la persona: es decir, que de todos y cada uno de ellos resulte lo que es patrimonio común a partir del art. 1.1 GG». Siguiendo con su argumentación afirma que: «Sin duda, se hallan los orígenes de los derechos fundamentales asociados a diferentes ideas políticas y sociales, habiendo representado en cada caso una respuesta a los específicos desafíos de cada época. No obstante, con independencia de las inflexiones de la idea de justicia, tiene ésta un contenido material supratemporal circunscribible más que a cualquier otro concepto al de la dignidad humana»(Benda: 2001: 122) ${ }^{21}$.

Efectivamente, si se hiciera un ejercicio de traslación y simulación a las situaciones en las que los menores se ven atrapados por el turismo sexual existirían argumentos para apoyar la idea anterior de Benda de los estrechos vínculos entre lo que representan las nociones de dignidad y justicia para salvaguardar los derechos de la infancia explotada.

20 BENDA, E., «Dignidad humana y derechos de la personalidad». En BENDA, E.; MAIHOFER, W.; VOGEL, H.; HESSE, K.; HEYDE, H., Manual de Derecho Constitucional, Madrid, Marcial Pons, 2001, pp. 117-144.

21 Ob.cit. 
Un autor en la tradición constitucionalista alemana como Häberle (2000: 88) 22 manifiesta que la dignidad se coloca como la «premisa antropológica y cultural» sobre la que deben construirse al mismo tiempo un Estado sólido y su Carta Magna, defendiendo la idea que la dignidad debe tener un lugar preponderante en los textos constitucionales porque sin ella se desmoronan y vacían de contenido los derechos fundamentales que tanto tiempo han tardado en consolidarse en los regímenes democráticos de este siglo XXI.

A partir de todas las aportaciones doctrinales reflejadas desde la perspectiva constitucionalista se podría configurar un estado de la cuestión en el que destacan los dos siguientes elementos esenciales:

a) La defensa de la dignidad en los menores afectados por las consecuencias del turismo sexual que multiplica sus efectos por la utilización de las nuevas tecnologías de la información y comunicación en el actual mundo globalizado no puede configurarse como un principio o valor genérico con lectura separada de los derechos fundamentales sino que para que tenga sentido pleno y se extienda una mayor seguridad jurídica para estas minorías amenazadas debería estar explícitamente recogido en las Constituciones de los países democráticos no sólo como un derecho fundamental más, sino quizás como el básico del que emana el resto. Por ello, y en relación a la estructura de la CE de 1978 cabe hacerse algunas preguntas: ¿Qué criterios fueron los que determinaron en el proceso constituyente que la dignidad no se equiparara en cuanto a importancia y rango al conjunto de derechos fundamentales y libertades públicas que gozan de las mayores garantías jurídico-constitucionales? ¿Primaron más para ello unas premisas filosóficas alejadas de la técnica constitucional o fue más bien al contrario lo que se consensuó en torno a la dignidad?

b) Una de las razones que pueda haber derivado en no incorporar la dignidad como un derecho fundamental equivalente en garantías a los que se configuraron como tales, pueda ser su complicada y abstracta formulación en cuanto a lo que realmente entraña la dignidad, frente a otros derechos como vida, libertad de expresión, asociación, intimidad personal familiar y personal, etcétera, que, al menos a priori, pueden concretarse y definirse con más precisión a efectos prácticos cuando se solicita su defensa por la ciudadanía en el marco del ordenamiento jurídico.

22 HÄBERLE, P., «El estado constitucional europeo», Cuestiones constitucionales: revista mexicana de derecho constitucional, 2, 2000, pp. 87-104.

(C) UNED. Revista de Derecho UNED, núm. 13, 2013 


\section{FACTORES INTERNOS Y EXTERNOS VINCULADOS A LA DIGNIDAD DEL MENOR Y LIBRE DESARROLLO DE SU PERSONALIDAD}

Antes de entrar propiamente en el contenido de este apartado, se ha considerado realizar un breve acercamiento previo a diferentes consideraciones doctrinales desde el Derecho Constitucional que servirán a continuación para encuadrar con mayor precisión y detalle el tema.

Comenzando por De Otto (2008: 17) ${ }^{23}$ que entiende que en el mismo concepto que entraña la Constitución, su fundamento orientador ha de basarse en la «jerarquía entre normas», se podría vislumbrar que trasladado esto al planteamiento que en el período constituyente español previo a la promulgación de la CE se otorgó a la dignidad y el libre desarrollo de la personalidad, el principio jerárquico bien pudo ser el que se utilizó para realizar la separación diferenciada entre los derechos de la persona recogidos en el artículo 10 de la CE (de especial significación en lo que se refiere a la temática de esta tesis doctoral) y los derechos fundamentales y libertades públicas del Título I fuertemente protegidos en comparación con los anteriores.

Ferrajoli (2004) ${ }^{24}$ manifiesta que una de las esencias del denominado "constitucionalismo rígido» ha sido dotar a los derechos fundamentales y libertades públicas frente al resto de principios, reglas y valores de unas importantes limitaciones de estos últimos. Algo similar ha podido suceder en lo que a la dignidad concierne en España, dado que haber concentrado con más esfuerzo la atención garantista en una determinada dirección, haya provocado que en otras ramas del Derecho Público que tienen como referente permanente y constante la norma suprema no se haya desarrollado todo lo que sería ideal una legislación en torno a la defensa de la dignidad y libre desarrollo de la personalidad como premisa de partida.

Según Serna (1995: 290)25, « la dignidad de la persona humana no debe situarse en el mismo nivel que la libertad, la igualdad o el pluralismo político», lo cual refleja que existe una corriente doctrinal

23 DE OTTO Y PARDO, I., Derecho Constitucional. Sistema de Fuentes, Barcelona, Ariel, 2008 2004.

24 FERRAJOLI, L., Derechos y garantías: la ley del más débil, Madrid, Trotta,

25 SERNA, P., "La dignidad de la persona como principio de Derecho Público», Derechos y Libertades: revista del Instituto Bartolomé de las Casas, II (4), 1995, pp. 287-306. 
partidaria que la dignidad se encumbre a un plano superior en su comparación con tres de los valores superiores de la $\mathrm{CE}$ recogidos en su artículo 1.1, por lo que se podría presumir que los derechos de la persona del artículo 10 de la CE pasarían a un primer escalafón en cuanto a su relevancia jurídica, por encima de los enumerados como valores superiores y los derechos fundamentales y libertades públicas. Serna (1995: 290) ${ }^{26}$, en su argumentación acerca de la dignidad, realiza igualmente una crítica tanto a posturas doctrinales como otras fuera del ámbito científico que para este autor han pretendido ocultar, cuando menos, la importancia de la dignidad en el constitucionalismo español. Asimismo, enfatiza el carácter «racional» de la dignidad desde posicionamientos teóricos filosóficos para diferenciarla de los tres valores superiores antes citados de la CE en el sentido que: «la libertad, la igualdad y el pluralismo pueden adoptar fácilmente la forma de valores, sin necesidad de referencia objetiva alguna, sino por virtud de un acto de voluntad que los asume individualmente o los 'propugna' formal y colectivamente (art. 1.1 CE), haciendo en todo caso innecesaria la argumentación racional, puesto que los valores son precisamente el sustituto positivista del ser, es decir, del bien, como expuso Heidegger»(Serna, 1995: 291) ${ }^{27}$.

Es significativo que este autor no haga alusión a la justicia, el cuarto de los valores superiores que se recogen en el artículo 1.1 de la $\mathrm{CE}$, dato que pudiera hacer pensar que ésta tiene una serie de connotaciones jurídico-racionales que le acercan más a la dignidad y libre desarrollo de la personalidad.

Por su parte, y a diferencia de lo que se ha recogido en anteriores párrafos, García García (2003: 30) ${ }^{28}$ defiende que los «valores superiores» de la $\mathrm{CE}$ debieran ser la «dignidad, libertad e igualdad» como sustentadores del resto de derechos de la personalidad y fundamentales. Por tanto, incluye a la dignidad como «valor superior» nombrado en primer lugar, con un mismo equilibrio para la dignidad y la libertad e igualdad, e ignorando a la justicia y el pluralismo político.

Todo ello refleja que ha sido amplia la discusión desde diversas vertientes doctrinales en torno a la esencia jurídica que debe asumir el concepto de dignidad como derecho de la persona recogido en la $\mathrm{CE}$, lo cual sirve al deseo de comprender lo que a continuación se expondrá acerca de un elaborado y bien documentado informe

26 Ob.cit.

27 Ob.cit.

28 GARCÍA GARCÍA, C., El derecho a la intimidad y dignidad en la doctrina del Tribunal Constitucional, Murcia, Universidad de Murcia, Servicio de Publicaciones, 2003. 
realizado conjuntamente por el Instituto de Derecho Internacional en Materia de Derechos Humanos (IHRLI), la Facultad de Derecho de Paul University, la Comisión Interamericana de Mujeres(CIM), el Instituto Interamericano del Niño (IIN) y la Organización de los Estados Americanos (OEA) ${ }^{29}$ relativo al tráfico de mujeres y menores en cuanto a su investigación y seguimiento se refiere.

En el mismo se definen una serie de factores internos y otros externos a modo de causas que contribuyen a la vulneración de la propia dignidad de estas minorías atrapadas en el tráfico de la explotación sexual. Dentro de los internos, destacar entre los diez concretos factores que se enumeran en el ámbito geográfico prioritariamente de los países que constituyen América Latina, los siguientes: «Pobreza» (se especifica que puede ser propia, es decir, de las mujeres o menores como personas objeto de abusos o circunscrita al círculo más cercano de familia o, en su ausencia, la figura del tutor o la tutora), «Falta de alternativas económicas», "Analfabetismo ${ }^{30}$ /educación mínima», «Abuso físico o sexual», «Disolución de la familia», «Falta de un hogar», «Uso de drogas», «Integración de bandas» y «Orientación sexual». De todos ellos, hay algunos que reclaman más la atención que otros de quien escribe estas líneas porque afectan al mismo sustrato en el que nace y se desarrolla una persona en lo que a su dignidad se refiere, en concreto la «disolución de la familia» y la "falta de un hogar». A nadie se le escapa que la familia es el primer eslabón en su futuro proyecto vital que tiene cualquier ser humano cuando viene al mundo. Crecer y vivir en el seno de una familia de las conocidas con el adjetivo calificativo de «desestructuradas» equivale en muchas ocasiones de forma automática a la inexistencia propiamente de vínculos familiares, lo que se traduce en el dicho popular español de «estar sola o solo en el mundo». Esta concatenación de hechos facilita que en los países subdesarrollados, niñas y niños, puedan ser más fácil e impunemente captadas y captados por las mafias organizadas para ser explotados en sus formas más abruptas, siendo una de las grandes fuentes de financiación de estos colectivos delictivos el turismo sexual, aunque no se puede afirmar de forma taxativa e incólume que sea un fenómeno que se contextualice sólo en un determinado ámbito geográfico sino que, cada vez más, en torno a lo que ya se ha explicitado en anteriores párrafos se expe-

29 Realizada la consulta al mencionado informe el día 16 de junio de 2012 en: http://www.iin.oea.org/proder/explotaci\%C3\%B3n.sexual/conclusiones.trafico.pdf.

30 En cuanto al analfabetismo no se diferencia si se trata de su grado máximo conocido como integral (no saber escribir ni leer) o funcional (saber leer y escribir aunque con dificultades pero con la imposibilidad de poder comprender el significado de las palabras en sus acepciones más básicas). 
rimenta también en grandes ciudades con alto índice de desarrollo social y económico en torno a la modalidad del turismo emergente y con singularidad propia de ferias y congresos. Merece atención para su análisis y reflexión en esta dirección, pertinente para el objeto de estudio, algunos datos ofrecidos en un trabajo publicado en 2006 por Fernanda Ezeta, perteneciente a la Organización Internacional para las Migraciones México (OIM México), con fundamento en el Informe Anual sobre Trata de Personas del Departamento de Estado de los Estados Unidos de América ${ }^{31}$ :

«[...] en el caso de trata con fines sexuales, una abrumadora mayoría del $98 \%$ es ocupado por mujeres y niñas».

Es una nítida y a la vez lamentable constatación que la condición de menor y mujer en circunstancias socioeconómicas de graves dificultades y en numerosas ocasiones de muy complicada solución, por no categorizarlas como imposibles, aumenta exponencialmente hasta cifras porcentuales muy elevadas las posibilidades de ser víctima de tráfico sexual con motivos comerciales.

Esta autora en consonancia con lo anterior argumenta las siguientes apreciaciones personales interesantes expuestas en el siguiente extracto:

«La trata de mujeres debe entenderse en el amplio contexto de desigualdad y violencia estructural a las que están sujetas. En todas las sociedades, en mayor o menor grado, las mujeres y las niñas enfrentan constantes violaciones a sus derechos humanos y/o a sus derechos económicos en los lugares de origen. En general, las mujeres están más afectadas por la violencia y la discriminación de género en la educación, la inequidad laboral, caracterizada por la segregación ocupacional y una representación desproporcionada en los sectores informales de empleo. Todo ello trae como consecuencia una muy particular vulnerabilidad así como una enorme inseguridad económica y por lo tanto la propensión a migrar, generalmente en forma irregular, a pesar de los riesgos e implicaciones que esto conlleva.

Las mujeres por lo general experimentan un acceso desigual a los canales formales para emigrar, dada la poca o pobre información sobre los riesgos potenciales en el trayecto y la ausencia de redes de servicios especializados a lo largo de las rutas migratorias especialmente en términos de salud y asistencia médica de emergencia para aquellos casos en que tienen poco o ningún poder de decisión

31 Efectuada la consulta al trabajo de Fernanda Ezeta el día 16 de junio de 2012 en http://www.oas.org/atip/reports/trata.aspectos.basicos.pdf. 
para evitar relaciones sexuales peligrosas o no deseadas durante el trayecto. Igualmente, las oportunidades de empleo, tanto en los países de tránsito como en los de destino, suelen ser más limitadas para las mujeres migrantes. Los sectores donde tradicionalmente existe "demanda femenina" son en su mayor parte informales, poco protegidos y no regulados, lo que las hace más dependientes de redes de intermediarios sea de tratantes o traficantes (conocidos también como polleros o coyotes). Estos, entre muchos otros factores, hacen a las mujeres más proclives a ser presa de la trata y la explotación en todo el mundo.

La desintegración de la antigua Unión Soviética y la consiguiente inestabilidad política y económica han conducido a un importante aumento de trata de mujeres provenientes de Europa Central y Oriental. Al respecto, la OIM estima que cada año alrededor de medio millón de mujeres son sometidas en condición de trata en los mercados de prostitución locales europeos. Igualmente entre 2,500 y 3,000 mujeres de estas regiones son explotadas en Israel» ${ }^{32}$.

Por tanto, Fernanda Ezeta, entiende que este fenómeno es un suceso que se puede localizar en pleno siglo XXI en cualquier parte del mundo por la inercia de los efectos globalizadores de nuestro planeta.

En lo concerniente a los factores externos se citan siete concretos y siendo todos importantes, destacar el último a los efectos del interés de la temática planteada:

"Discriminación por género», "Objetivización de los niños», «Facilidad de la migración / fragilidad de los controles fronterizos», «Políticas de globalización», «Corrupción pública», «Existencia de redes de tráfico», "Existencia de demanda (prostitución/striptease/ turismo sexual».

Se constata que en la denominada «Existencia de demanda», el «turismo sexual» es un elemento diferenciador remarcado junto a los otros dos mencionados de "prostitución» y «striptease» que se encuentran en la raíz de los problemas consustanciales desde una óptica externa a la condición simultánea de mujer y menor, empleadas para fines tan condenables como execrables que afectan a la dignidad de la persona en su fundamentación más íntima y privada y de la que ningún ser humano puede ser desprotegido porque ello conllevaría y conlleva de hecho en la realidad presente la indefensión

32 Realizada la consulta al trabajo de Fernanda Ezeta el día 16 de junio de 2012 en http://www.oas.org/atip/reports/trata.aspectos.basicos.pdf. 
y desprotección jurídica en los términos más abyectos y perseguibles para su erradicación.

Todo ello se puede apoyar en exhaustivos trabajos en el marco de la cooperación al desarrollo que realizan organizaciones gubernamentales y no gubernamentales (ONG,s). Entre estas últimas, sobresale un documento de Médicos del Mundo titulado «La prostitución desde una perspectiva de los derechos humanos ${ }^{33}$, elaborado en formato a modo de Ponencia con destino a la Comisión Mixta Congreso de los Diputados-Senado por Alicia Bolaños Naranjo, Vocal de Derechos Humanos de Médicos del Mundo-España, en el que explica que:

«La prostitución no es una institución femenina, es controlada por hombres y mantenida mediante la violencia; si bien a una pequeña escala local puede ser, a veces, un negocio consensuado sobre el que la mujer ejerce un cierto control, la realidad demuestra que se trata de un grupo minoritario, de apenas un 5\%, donde la mujer tiene libertad de consentimiento; libertad que, a estas alturas debemos entenderla en un concepto democrático y no hacer manidas, retorcidas y sesgadas interpretaciones de la misma porque no se encuentra ninguna de estas condiciones atenuantes en el estado actual y global de la prostitución, cuyo análisis es imposible sin la intrínseca relación con el tráfico, la globalización y el tráfico de personas con fines de explotación sexual. El mercado mundial del sexo es casi completamente coactivo, mantenido a base de altos niveles de violencia y basado en la completa subordinación de las mujeres».

Esta misma autora citando a Seeger, sigue argumentado en apoyo a los factores internos y externos que se han enumerado anteriormente focalizados en menores y mujeres como minorías objeto de tráfico y turismo sexual que «la mayor parte del tráfico se ajusta a una de estas cuatro modalidades: según la primera, mujeres que ejercen la prostitución en su país son intercambiadas a otro país por sus chulos. Según la segunda, las chicas son vendidas por las familias pobres para la prostitución -en algunos casos lo saben y en otros se les dice que la chica será empleada doméstica o trabajadora en una fábrica-; una vez prostituida el escaso valor de la chica para su familia baja incluso más. Según la tercera, las mujeres son arrastradas al mercado sexual con falsas promesas; primero son contratadas como camareras o criadas y luego se le obliga a ejercer la prostitución. Finalmente y cuarto supuesto, existen evidencias importantes de un

33 Documento consultado el día 16 de junio de 2012 y a cuyo contenido completo se puede acceder en la siguiente dirección electrónica: http://www.observatorioviolencia.org/upload_images/File/DOC1166017160_Prostitucion_perspectivaddhh.pdf. 
mercado esclavista que empieza con el secuestro de la mujer o la chica en regiones sumidas en la pobreza.

Estos son los orígenes de una red sexual mundial donde los cuerpos de las mujeres son simple mercancía y donde el miedo a contraer el sida alimenta la demanda de chicas cada vez más jóvenes. El tráfico internacional de niñas y mujeres continúa, cada vez más, en su auge prosperando a base de las desigualdades económicas entre los hombres y mujeres a todos los niveles y entre distintas regiones a nivel mundial. Nuevos países y regiones entran en el comercio sexual conforme se desvanece su riqueza, y donde hay un hombre pobre, más pobre se encuentra la mujer; de ahí que el tráfico de mujeres se convierta en un vil negocio rentable y la inmigración, como recurso, resulte un destino para la esclavitud sexual, sin olvidar los estragos del turismo sexual; escenarios todos ellos que conducen a uno: la prostitución, donde los actores que mantienen este mercado son los proxenetas y los clientes, este último invisibilizado alevosamente hasta tiempos recientes, porque no hay oferta sin demanda y es que cuando se habla de prostitución conviene precisar que mujer prostituida, es aquella que vive en una sociedad prostituyente, es decir, que posibilita que las mujeres se prostituyan y donde existen hombres que demandan esta prostitución.

Intentaremos transmitir que la prostitución no es un trabajo, que no hay dignidad en su ejercicio del que se aprovechan muchas personas, que no son las que la ejercen, a costa de la salud mental y física (en muchos casos, para poder ejercerla las mujeres se vuelven o las vuelven drogodependientes), la baja autoestima, la pobreza, las condiciones sociales del país de origen que constriñen sus vidas, el consentimiento viciado de ellas, tan sólo por un beneficio económico que es fácil de obtener en un negocio de escasa inversión y demás circunstancias que conducen a que el $95 \%$ de las mujeres que la ejercen lo hagan sin el sentido de libertad al que debemos aludir siempre y no a la manida libertad alegada por un sector minoritario que pretende globalizar unos intereses muy personales perjudicando al inmenso resto; que no se puede legislar algo perjudicial socialmente y convertirse un Estado en cómplice de dicho perjuicio social por un grupo minoritario en el cual no pesan todas las circunstancias que inducen a la prostitución en la inmensa mayoría de los casos; que cualquier profesional del Derecho se cuestionaría la redacción del objeto contractual que supone el ejercicio de la prostitución, objeto que nadie quiere nombrar porque resulta un lenguaje desagradable y que es mejor obviar, cuando no se puede hablar de ella sin contar realmente en lo que consiste: felaciones (tragando o sin tragar el se- 
men), cunnilinguis, beso negro, griego, lluvia dorada, coprofilia, penetraciones vaginales y anales de objetos, penetraciones en grupos, etc.; donde la necesidad de su existencia no obedece a una necesidad real de nadie, otro argumento de manida insistencia, puesto que las necesidades y carencias afectivas que puede tener un hombre, las puede tener también una mujer y porque las necesidades de la persona no pueden ser ilimitadas, no vamos a convertir toda fantasía -e incluso las perversiones- en un trabajo, o aceptarlas sin más, si no evolucionaríamos como Holanda, donde se ha formado un partido pedófilo y a la que dedicaremos un apartado especial en esta intervención por ser el máximo exponente del fracaso de la reglamentación de la prostitución»(Seeger, 2001) ${ }^{34}$.

\section{LAS CONNOTACIONES DEL TURISMO SEXUAL EN LA PERSONALIDAD DEL MENOR}

El libre desarrollo de la personalidad conectada a la dignidad del menor es la segunda plasmación de los derechos de la persona reconocida en el artículo 10.1 de la $\mathrm{CE}$ sobre la que se proyectan peligros evidentes cuando se analizan los efectos que se pueden detectar respecto a su vulneración en niñas y niños que son víctimas de la explotación sexual en el ámbito turístico cualesquiera que sean las formas en las que se manifieste ésta.

Antes de entrar en consideraciones jurídicas, constatar que la «personalidad» es un concepto científico cuyo origen se adscribe a la disciplina de la Psicología que designa el conjunto de rasgos tipológicamente estables de cada persona y que le confiere características únicas frente al resto de sus semejantes. Por ello, su debida y especial protección en la normativa constitucional española así como en otros relevantes instrumentos jurídicos nacionales e internacionales le confiere una singularidad y especificidad propias. Cuando alguno o, llevado a su más cruel extremo, todos los rasgos de la personalidad se ven alterados de forma brusca y violenta por la acción de cualquier otra persona, se distorsionan con rapidez aspectos trascendentales del ser humano, tales como su autoestima y percepción de autocontrol sobre sus actos que en sus últimas consecuencias trasladan una sensación de «obligada» dependencia emocional de los individuos que le agreden contra su propia seguridad física y libertad de movimientos (convendría realizar un sencillo ejercicio de empatía para conocer, por ejemplo, el sentimiento de menores que en sus países de

\footnotetext{
34 SEEGER, J., Atlas del estado de la mujer en el mundo, Madrid, Akal, 2001.
} 
origen se ven forzados a la realización de actos diarios y numerosos que van contra su voluntad para satisfacer las ansías de enriquecimiento ilícito de personas, sin escrúpulos, que les fuerzan a jornadas extenuantes en la prostitución que demanda el turismo sexual, inclusive en algunos casos y este fenómeno no por menos conocido no se le puede restar trascendencia, de mostrar sus cuerpos desnudos a través de una cámara incorporada al equipo informático para que los demandantes a muchos kilómetros probablemente de distancia abonen por medios electrónicos de pago grandes cantidades de dinero a las mafias que organizan todo este entramado criminal).

Desde la orientación constitucional, un primer apunte interesante es que los ataques a la dignidad y personalidad del menor podrían ubicarse en lo que parte de la doctrina entiende como "crisis» de la denominada Teoría de la Constitución (Asensi, 2002: 532) ${ }^{35}$ por cuanto, junto a otros principios genéricos y orientadores en la $\mathrm{CE}$, diera la impresión que no han sido suficientemente tratados en su debida amplitud y extensión, si se muestra una comparativa sistemática con los derechos fundamentales y libertades públicas, lo que ya se comentaba en párrafos anteriores.

Con el ánimo de realizar en este punto una breve incursión a modo exclusivamente informativo de cotejo con la realidad de otros contextos geográficos distintos al español pero cercanos por cuestiones de cultura y lengua común como son los países de habla hispana de América Latina y el Caribe, un ejemplo que coincide con lo expuesto por Asensi es lo que ha ocurrido en Perú en el que reglas de primer rango constitucional como la dignidad y el libre desarrollo de la personalidad también se han visto relegadas a un segundo papel en la escala que prioriza a los derechos fundamentales como vértice superior de las Constituciones más recientes, como afirma García Belaunde (2010: 511) ${ }^{36}$.

El pensamiento de este autor es también un reflejo de la influencia demostrable y real que la $\mathrm{CE}$ ha tenido sobre los posteriores textos constitucionales de las emergentes democracias en América Latina en los últimos años del pasado siglo XX respecto a todo lo que se refiere a la separación entre principios y valores con una redacción en términos más abstractos y de formulación teórica (dignidad y libre desarrollo de la personalidad), por un lado, y los derechos fun-

35 ASENSI SABATER, J., «Recensiones». En López Pina, A.; Gutiérrez Gutiérrez, I., Elementos de derecho público, Madrid, Marcial Pons, 2002, pp. 532-537.

36 GARCÍA BELAUNDE, D., "Doctrina constitucional peruana en el siglo XX», Historia constitucional: Revista Electrónica de Historia Constitucional, 11, 2012, pp. 507-511. 
damentales a los que se ha otorgado una concreción con límites en lo que a su defensa y protección concierne más definidos.

No es desdeñable aplicar en este punto la postura que De Agapito (2009: 103) ${ }^{37}$ refleja como el enfrentamiento de intereses que ha tenido eco con la función teórica de este tipo de valores en el mundo jurídico en general.

Probablemente, en la redacción de la CE de 1978, resultado del consenso nacido en la etapa de la Transición española entre los principales y más representativos partidos políticos de esos instantes históricos, se acordara que principios primordiales implícitos en la propia naturaleza humana como la dignidad y el libre desarrollo de la personalidad, entre otros, debían hacerse un hueco entre los primeros artículos de la Carta Magna.

Hoy en día, y conectado a la idea anterior, conviene reflexionar sobre las trascendentales consecuencias que para el desarrollo integral de la personalidad y el proyecto vital de niñas y niños tiene la «alfabetización digital», cuando existe una inadecuada utilización de las TIC, en lo que al objeto de estudio se refiere, que viene definido por la característica de amplia «facilidad de uso» de las nuevas tecnologías de la información y comunicación. Para Vera Santos, Cervelló García y Ríos Insua, en un trabajo de su autoría sobre la democracia electrónica, implica su familiaridad «sin entrenamiento ni conocimiento previo» (Vera Santos; Cervelló García; Ríos Insua, 2006: 5) ${ }^{38}$.

Por su parte, Sánchez Barrilao (2009: 117-118) ${ }^{39}$ introduce en esa discusión el factor de la "globalización» como auténtico dilema que debe ser enfrentado desde una óptica constitucionalista, en el que las nuevas tecnologías de la información y comunicación acercan a la sociedad actual a innumerables retos jurídicos que deben resolverse con prontitud en lo que el autor define como "sociedad del riesgo" (referida no solamente al contexto español sino al resto del mundo, con especial énfasis en las naciones más desarrolladas).

Si se despliega una reflexión seria sobre lo que implica para un menor el derecho constitucionalmente extendido de la dignidad y

37 DE AGAPITO SERRANO, R., «La Unión Europea y la globalización», Revista de derecho constitucional europeo, 12, 2009, pp. 101-114.

38 VERA SANTOS, J.M.; CERVELLÓ GARCÍA, G.; RÍOS INSUA, D., «E-democracia-cm y iparticipa Móstoles! promoción de la participación ciudadana con las TIC». En Ponencias del Congreso Tecnimap 2006, Sevilla, 30 de mayo a 2 de junio, 2006, pp. 1-6.

39 SÁNCHEZ BARRILAO, J. F., «El derecho europeo y globalización: mitos y retos en la construcción del Derecho Constitucional Europeo囚, Revista de derecho constitucional europeo, 12, 2009, pp. 115-150. 
libre desarrollo de la personalidad hoy en día y se abre a la imaginación el peor escenario posible alrededor de lo que conlleva el empleo de las TIC por parte de las organizaciones que controlan el negocio del turismo sexual, se podría estar acuerdo que, frente a concepciones relativamente recientes en el tiempo que fomentan la construcción, en ocasiones «utópica» por las lamentables noticias a las que se tiene acceso en los medios de comunicación social, de las bases de una convivencia sostenida en el «interés superior» del menor como es el caso de España, la realidad diaria que traduce esa «sociedad del riesgo» en palabras de Sánchez Barrilao es contradictoria con esa defensa de la seguridad jurídica del menor por cuanto los ataques que sufren niñas y niños por las organizaciones criminales del turismo sexual resquebrajan lo que la $\mathrm{CE}$ fomenta en torno a la dignidad y el libre desarrollo de la personalidad como cimiento para una futura consolidación del proyecto vital de toda persona que ha experimentado una infancia sin sobresaltos y un acogedor y agradable orden familiar y social.

Como hilo continuador y por sus evidentes relaciones estrechas con el Derecho Constitucional, es conveniente recordar, en las líneas siguientes, algunas normas internacionales que coinciden en las aportaciones de preceptos constitucionales sobre dignidad y libre desarrollo de la personalidad.

Antes de comenzar el análisis de esta normativa, y para documentar el estado de la cuestión, es importante introducir unas oportunas reflexiones sobre lo que implica la misma existencia e interpretación de los textos constitucionales en su relación con otros ámbitos del acontecer social, como es el caso que ocupa la atención. En una primera aproximación, Aragón entiende que «la realidad política y social y la misma historia no son elementos que integren la Constitución y el Derecho Constitucional y por ello no pueden convertirse en razones capaces por sí solas de dotar de sentido a las normas constitucionales determinando su aplicación, pero sí son elementos imprescindibles para comprender la Constitución y orientar y contrastar los criterios jurídicos-interpretativos que operan en cada acto de explicación o de aplicación de las normas constitucionales» (Aragón, 1998: 29) ${ }^{40}$.

A partir de la argumentación de este autor dada al inicio, cabría preguntarse si los intentos de resolver con eficacia todas aquellas circunstancias que, ampliadas por los efectos de las nuevas tecnologías

40 ARAGÓN REYES, M., «Encuesta sobre la orientación actual del derecho Constitucional», Teoría y Realidad Constitucional, 1, 1998, p. 29. 
de la información y comunicación, rodean la explotación sexual de menores en el mundo del turismo, como un posible ejemplo de esa «realidad social» en palabras de Aragón, encuentra una respuesta en los textos constitucionales o, en su defecto, hay que acudir a otras fuentes jurídicas para su interpretación.

Otro punto de vista diferente es incorporado por Pedro de Vega, para el que «la historia del Estado Constitucional es precisamente la historia de las transformaciones de esos valores, principios y exigencias que, definidos y explicitados previamente en la realidad social, se integran luego en la normativa constitucional» (De Vega, 1988: 84) ${ }^{41}$. Desde el enfoque que se pretende dar a esta investigación, el alineamiento con la postura de Pedro de Vega es más claro respecto al de Aragón, por cuanto, tiene más cabida lógica estar de acuerdo que es la misma «realidad social» la que marca la impronta, por medio de «esos valores, principios y exigencias», enunciados por Pedro de Vega, y que fundamentan toda Constitución cuando se prepara y elabora en la fase previa a su aprobación y vigencia para la ciudadanía.

Por su parte, Ferrando expone otro matiz interesante relativo a que «[...] toda sociedad políticamente organizada tiene su Constitución, porque en ella existe un conjunto de normas consuetudinarias relativas al modo y ejercicio del poder, la designación de sus titulares y sus competencias, etc.» (Ferrando, 1992: 722) ${ }^{42}$.

En distinto orden de ideas, existen observaciones pertinentes acerca de lo que acaece en las sociedades del siglo XXI, en relación con lo que implican las normas jurídicas supremas. Así, Gambino, afirma que "la crisis del estado contemporáneo ha abierto una crisis profunda de la Constitución tanto en su aspecto de proyecto como en el de garantista, es también cierto que no parece haber decaído la necesidad de orden y seguridad que ha justificado la existencia histórica y que ahora impulsa a buscar tales armonías en los niveles superiores de regulación y garantía [...]»(Gambino, 2005: 113) ${ }^{43}$.

Esa justificación de «la necesidad de orden y seguridad» que subraya Gambino, se ve reflejada de forma implícita en otros apoyos doctrinales que se retrotraen a épocas anteriores, como realizaron recientemente Núñez Rivero, Goig Martínez y Núñez Martínez: «La

41 DE VEGA GARCÍA, P., «El tránsito del positivismo jurídico al positivismo jurisprudencial en la doctrina constitucional», Teoría y Realidad Constitucional, 1, 1998, pp. 65-87.

42 FERRANDO BADÍA, J., Estudios de Ciencia Política, Madrid, Tecnos, 1992.

43 GAMBINO, S., «El derecho constitucional común europeo entre teoría constitucional y praxis», Cuadernos de Derecho Público, 24. 2005, pp. 111-132. 
concepción de la Constitución como un sistema de normas, marcada de un profundo espíritu revolucionario, tiene como base ideológica la ruptura con el Antiguo régimen y la necesidad de ordenar el Estado, pero no como consecuencia de una serie de decisiones tomadas según surgen los distintos acontecimientos, sino de la creencia de establecer de una sola vez y para siempre un esquema de organización en el que se encierra la vida toda del Estado» (Núñez Rivero, Goig Martínez y Núñez Martínez, 2010: 136) ${ }^{44}$.

La posición de estos últimos autores sí parece estar más en consonancia con lo expuesto por Aragón (1998: 29) ${ }^{45}$, que con el comentario de Pedro de Vega (1988: 84) ${ }^{46}$, línea argumentadora esta última, que coincide con la opinión que se defiende aquí: el Derecho, en muchas ocasiones, tiene que adaptarse a los acontecimientos sociales que cambian a una velocidad muy rápida, en un mundo como el que se vive, en el que los usos inadecuados de las nuevas tecnologías de la información y comunicación, originan constantes interrogantes en el ámbito jurídico.

También, y aparte de lo que significa en sí misma la Constitución, vinculada a la realidad social, remarcar la influencia que han tenido y tienen las sentencias del Tribunal Constitucional. Luís López Guerra (1998: 43) ${ }^{47}$, manifiesta esto anterior, por medio de lo que el autor expresa como actitud «seguidista» que tienen sus decisiones en la ciudadanía, y que el autor achaca a "parte de la doctrina».

En definitiva, se concluye, a partir del conjunto de las anteriores aportaciones, que no tiene sentido incluir problemas concretos en los textos constitucionales y, por ello, toda norma debe interpretarse de acuerdo con la realidad social del contexto en el que se desarrollan los hechos.

Una vez reflejadas estas observaciones preliminares, hay que referirse a la Resolución 8/12 de la Organización de las Naciones Unidas (ONU) a través del informe del Relator Especial sobre la trata de personas en su 28. a sesión celebrada el 18 de junio de 2008 que fue aprobada sin votación, con tratamiento especial para mujeres y niños ${ }^{48}$, establece una delimitación interesante de cuatro preocupa-

44 NÚÑEZ RIVERO, C.; GOIG MARTÍNEZ, J. M.; NÚÑEZ MARTÍNEZ, M., Teoría del Estado Constitucional, Madrid, Universitas, 2010.

45 Ob. cit.

46 Ob. cit.

47 LÓPEZ GUERRA, L., «Encuesta sobre la orientación actual del Derecho Constitucional», Teoría y Realidad Constitucional, 1, 1998, pp. 43-44.

48 Consulta realizada el 16 de junio de 2012 en la siguiente dirección electrónica: ap.ohchr.org/documents/S/HRC/resolutions/A_HRC_RES_8_12.doc. 
ciones directamente relacionadas con el libre desarrollo de la personalidad y que de forma reiterada se pueden advertir cuando las nuevas tecnologías de la información y la comunicación se utilizan para multiplicar los servicios que demandan potenciales beneficiarios del turismo sexual en cualquier parte del mundo:

«a) El elevado número de personas, especialmente mujeres y niños, en particular de países en desarrollo y países con economías en transición, que son objeto de tráfico con destino a países desarrollados, así como dentro de una misma región o Estado o de una región o Estado a otro».

Se advierten dos aspectos dignos de destacar:

- En primer lugar, el Relator Especial se refiere a los países en desarrollo y a aquellos otros a los que alude con la expresión «economías en transición» como los destinos principales donde se capta a mujeres y menores por medio de constantes engaños y falsas promesas de una vida mejor que tienen su triste final en la tremenda realidad a la que se ven abocados cuando llegan a aquellos otros países descritos como supuestos "paraísos» con unos aparentes estándares de calidad de vida más elevados. ${ }^{49}$

- En segundo término, también se advierte que el turismo sexual puede ser concebido como un fenómeno «local», por tanto, no solamente con connotaciones cercanas a la globalización, que se da entre zonas o regiones de un mismo país, sobre todo en aquellos Es-

49 Fernanda Ezeta de OIM México expone en su documento de trabajo titulado «Trata de personas: Aspectos Básicos», ya citado con anterioridad, que «es frecuente encontrar en los medios de comunicación y sobre todo en Internet noticias que abordan los siguientes temas:

- Trata de mujeres para el mercado matrimonial, entre países asiáticos o desde Latinoamérica, Asia y África hacia Europa, Japón y los Estados Unidos.

- Caravanas de mujeres movilizadas en contra de su voluntad o bajo condición de trata e instaladas en las cercanías de bases militares para entretenimiento y uso sexual de oficiales y soldados.

- Mujeres en condición de trata explotadas como mano de obra barata y que trabajan sin ninguna protección laboral en sectores específicos como el empleo doméstico o la industria sexual.

- Mujeres ofrecidas como esclavas en sitios de Internet, donde se les promociona explicando su capacidad y resistencia al dolor, a la tortura y todo lo que puede hacerse con ellas.

- Miles de mujeres atraídas por un supuesto contrato de trabajo rentable y que terminan destinadas a burdeles o clubes nocturnos de diferentes lugares del mundo.

- Mujeres y niñas provenientes de áreas rurales que son vendidas y coaccionadas para llenar la demanda de turismo sexual.

- Anuncios y promociones turísticos sobre mujeres y niñas exóticas a las que se puede acceder fácilmente en un vuelo chárter con todo incluido». 
tados donde existen unas grandes diferencias económicas, culturales y sociales entre las ciudades y los pueblos. No es infrecuente escuchar, leer o ver en las noticias de los medios de comunicación que en muchas zonas subdesarrolladas del planeta los padres venden a sus hijas e hijos a organizaciones que tienen como finalidad su explotación sexual en las grandes urbes.

«b) La intensificación de las actividades de la delincuencia organizada transnacional y nacional, así como de otros que se lucran con la trata de personas, especialmente mujeres y niños, sin importarles las condiciones peligrosas e inhumanas a que someten a sus víctimas y en flagrante violación de la legislación interna y de las normas internacionales.

c) El uso de las nuevas tecnologías de la información, en particular Internet, con fines de explotación de la prostitución ajena, la pornografía infantil, la pedofilia, y cualquier otra forma de explotación sexual de los niños, así como la trata de mujeres con fines matrimoniales y de turismo sexual;

d) El alto nivel de impunidad de que se benefician los traficantes y sus cómplices y la denegación de derechos y justicia a las víctimas de la trata».

El Relator Especial con el objetivo de prevenir todos estos hechos en la medida de sus posibilidades, hace un llamamiento a los Gobiernos para que a través de una serie de recomendaciones se intente la reducción y eliminación de las prácticas contra el libre desarrollo de la personalidad de mujeres y niños, si bien es cierto que algunas de ellas más pueden catalogarse como una loable manifestación de buenos y lícitos deseos más que traducibles en acciones concretas y específicas por medio de las cuales se pueda comprobar, al menos con unas estadísticas fiables de una determinada periodicidad, si son efectivas en su despliegue por los responsables gubernamentales:

«a) Adoptar medidas apropiadas para combatir las causas fundamentales, incluidos los factores externos, que propicien la trata de personas con fines de prostitución y otras formas de comercio sexual, matrimonios forzados y trabajos forzados, la esclavitud o prácticas análogas a la esclavitud, la servidumbre o la extracción de órganos, entre otras cosas, fortaleciendo las leyes vigentes o considerando la posibilidad de promulgar leyes contra la trata de personas y adoptar planes de acción nacionales a fin de proteger mejor los 
derechos de las víctimas de la trata y castigar a los autores tanto por la vía civil como por la penal;

b) Tipificar como delito la trata de personas en todas sus formas y condenar y castigar a los tratantes, facilitadores e intermediarios, en particular, cuando proceda, mediante la imposición de sanciones a las personas jurídicas involucradas en el proceso de trata, sin que la participación de las víctimas o la presentación de acusaciones por parte de éstas sea una condición previa para el enjuiciamiento de los traficantes;

c) Velar por que se proporcione protección y asistencia a las víctimas de la trata con pleno respeto de sus derechos humanos;

d) Promover activamente la rehabilitación de las víctimas de la trata proporcionándoles acceso a atención y servicios médicos y psicológicos adecuados, incluidos los relacionados con el VIH/SIDA, así como refugio, asistencia jurídica y líneas telefónicas de ayuda;

e) Tomar todas las medidas apropiadas para que las víctimas de la trata no resulten penalizadas a causa de su situación y no vuelvan a convertirse en víctimas como consecuencia de medidas adoptadas por las autoridades gubernamentales, teniendo presente que son víctimas de explotación;

f) Adoptar o reforzar las medidas legislativas y de otra índole para desalentar la demanda que promueve todas las formas de explotación de personas y que da lugar a la trata de personas;

g) Establecer mecanismos, cuando proceda, en cooperación con la comunidad internacional, para luchar contra el uso de Internet para facilitar la trata de personas y los delitos relacionados con la explotación sexual y de otra índole y para fortalecer la cooperación internacional en las investigaciones y el enjuiciamiento de las actividades de trata facilitadas por el uso de Internet;

h) Proporcionar a las fuerzas del orden, a los funcionarios de inmigración, a los funcionarios de justicia penal y a otros funcionarios competentes, incluidos los que participan en operaciones de mantenimiento de la paz, formación en la prevención de la trata de personas y las formas de responder a ella de forma eficaz, incluida la tarea de identificación de las víctimas respetando plenamente sus derechos humanos;

i) Realizar campañas informativas para el público en general, incluidos los niños, con el fin de crear conciencia sobre los peligros 
de todas las formas de trata y alentar al público, incluidas las propias víctimas, a denunciar los casos de trata;

j) Cooperar entre todos y con las organizaciones intergubernamentales y no gubernamentales pertinentes para combatir eficazmente la trata de personas;

k) Mejorar el intercambio de información y la capacidad de reunión de datos como forma de promover la cooperación en la lucha contra la trata de personas, en particular mediante la recopilación sistemática de datos desglosados por sexo y por edad;

l) Estudiar la posibilidad de fortalecer los mecanismos regionales existentes destinados a combatir la trata de personas o establecer ese tipo de mecanismos donde no existan;

m) Considerar la posibilidad de firmar, ratificar y -en el caso de los Estados partes- aplicar los instrumentos jurídicos pertinentes de las Naciones Unidas, como la Convención de las Naciones Unidas contra la Delincuencia Organizada Transnacional y los Protocolos que la complementan, en particular el Protocolo para prevenir, reprimir y sancionar la trata de personas, especialmente mujeres y niños».

Como complemento argumentativo a esta Resolución 8/12 de la Organización de las Naciones Unidas (ONU), se expone, a continuación, lo que desde diferentes culturas constitucionales, se ha articulado en torno a los derechos humanos, con una especial consideración a los menores, como colectivo que sufre las consecuencias de los abusos de personas adultas en el contexto del turismo sexual.

Una primera referencia seleccionada es la de Legarre y Orrego (2010: 24) ${ }^{50}$, cuando tratan sobre el Derecho Constitucional de los Estados Unidos de América, invocando el elemento de «humanidad» que constatan en el pueblo norteamericano. Para estos autores, además, es esencial, la comprensión de «la universalidad de los derechos humanos entendidos como derechos naturales» (Legarre y Orrego, 2010: 25) ${ }^{51}$.

En materia de derechos humanos universales, Saiz Arnaiz refleja en una obra que obtuvo el Premio «Rafael Martínez Emperador» de 1998, que «no puede dejar de reconocerse que el amplio catálogo de derechos fundamentales presente en la Constitución hace muy difí-

50 LEGARRE, S.; ORREGO, C, «Los usos del derecho constitucional comparado y la universalidad de los derechos humanos», Revista Española de Derecho Constitucional, 88, 2010, pp. 11-38.

51 Ob.cit. 
cil la hipótesis de la existencia de un derecho reconocido en algún tratado firmado por España que no tenga su correspondiente constitucional [...]»(Saiz Arnaiz, 1999: 84) ${ }^{52}$.

Particularmente novedosa, es la diferenciación, en lo que a derechos humanos se refiere, de dos Estados con unas cercanas relaciones políticas, sociales, culturales y lingüísticas, como Alemania y Austria, pero que, a partir de la aportación doctrinal de Jakab, una nota distintiva es la consideración que tiene en Austria, el Convenio Europeo de Derechos Humanos, como «Derecho constitucional directamente aplicable» (Jakab, 2010: 152) ${ }^{53}$. A ello, añade, la supremacía en el país austríaco de "la teoría monista» (Jakab, 2010: $151)^{54}$, aunque reconozca, por medio de Ohlinger y Schweitzer, la existencia de compatibilidad entre la Constitución federal austriaca y la Ley Fundamental de Bonn (Jakab, 2010: 151) ${ }^{55}$.

En lo que respecta a la dicotomía entre teoría monista y dualista, es pertinente la reflexión del ucraniano Mirkine-Guetzévitch, para el que, en estos momentos, en lo que a la teoría dualista concierne, la misma «está en contradicción con el Derecho positivo, es ya incapaz de suministrar una explicación de los fenómenos de la vida internacional moderna» (Mirkine-Guetzévitch, 2008: 123) ${ }^{56}$, para después, defender la primacía de la teoría monista en los siguientes términos: "Las transformaciones radicales de la vida internacional de la post-guerra, la creación de formas nuevas del Derecho internacional, las nuevas realidades jurídicas no previstas por las teorías del Derecho internacional anterior, son las principales causas del éxito de la escuela austriaca, escuela monista en el sentido de reconocer la primacía del Derecho de gentes» (Mirkine-Guetzévitch, 2008: 123). ${ }^{57}$

En España, se destaca «la virtualidad y la fuerza expansiva» (Fernández de Casadevante y Jiménez García, 2006: 19) ${ }^{58}$ del Derecho

52 SAIZ ARNAIZ, A., La apertura constitucional al Derecho Internacional y europeo de los derechos humanos. El artículo 10.2 de la Constitución Española, Madrid, Consejo General del Poder Judicial, 1999.

53 JAKAB, A., «Dos paradigmas encontrados del pensamiento constitucional en Europa: Austria y Alemania», Revista Española de Derecho Constitucional, 88, 2010, pp. 131-162.

54 Ob. cit.

55 Ob. cit.

56 MIRKINE-GUETZÉVITCH, B., Derecho Constitucional Internacional, Madrid, Reus, 2008.

57 Ob.cit.

58 FERNÁNDEZ DE CASADEVANTE ROMANÍ, C.; JIMÉNEZ GARCÍA, F., El Derecho Internacional de los Derechos Humanos en la Constitución Española: 25 años de jurisprudencia constitucional. Cizur Menor, Navarra, Aranzadi, 2006.

(C) UNED. Revista de Derecho UNED, núm. 13, 2013 
Internacional de los Derechos Humanos en la CE, con el refuerzo que, para estos autores, supone la función desempeñada por el texto constitucional español, en lo que suscita la estabilización de «[...] las bases de la interacción entre el derecho Internacional de los Derechos Humanos y la tutela de los derechos y libertades fundamentales de la persona en el ordenamiento interno español» (Fernández de Casadevante y Jiménez García, 2006: 21) ${ }^{59}$.

En este breve repaso, Clavero, en el contexto geográfico de América Latina, realiza un análisis interesante en lo que se refiere a Bolivia, en su comparación con Venezuela, especificando, respecto a su Constitución de 2009, que «es la primera Constitución de las Américas que sienta las bases para el acceso a derechos garantizados por el Estado y poderes constituyentes del Estado [...]» (Clavero, 2010: $199)^{60}$. Es significativo, para Clavero, el artículo 8.1, reproducido en las dos lenguas oficiales del país:

«El Estado asume y promueve como principios ético-morales de la sociedad plural: ama quilla, ama llulla, ama suwa (no seas flojo, no seas mentiroso ni seas ladrón), suma tamaña (vivir bien), ñandereko (vida armoniosa), teko kavi (vida buena), ivi Maradi (tierra sin mal) y qhapaj ñan (camino o vida noble)» (Clavero, 2010: 200-201) ${ }^{61}$.

Son las expresiones, en concreto, «vivir bien», «vida armoniosa» y "vida buena», las que más recuerdan el ideal de los derechos fundamentales de los menores para el desarrollo de una infancia feliz, cuando son víctimas de agresiones y abusos sexuales en aquellos lugares que, pese a la existencia de una Constitución, e incluso, en algunos casos, novedosa en ciertos aspectos, hay una constatable ausencia de la puesta en práctica efectiva de medidas para esa protección constitucional por el lado de los poderes públicos.

\section{CONCLUSIONES}

En el trabajo de investigación se ha constatado, en primer lugar, el notable perjuicio que recae sobre la dignidad y el libre desarrollo de la personalidad de niñas y niños, víctimas del control que, sobre ellas y ellos, ejercen las mafias que intentan atraer una clientela con un perfil muy definido (hombres con elevado poder adquisitivo) hacia los destinos turísticos en los que se muestra una clara violación

59 Ob.cit.

60 CLAVERO, B., "Apunte para la ubicación de la Constitución de Bolivia», $R e$ vista Española de Derecho Constitucional, 89, 2010, pp. 195-217.

61 Ob. cit. 
de los derechos más inherentes a la persona por el hecho mismo de ser persona, potenciado por el masivo uso de nuevas tecnologías de la información y comunicación. Los daños en las vidas de millones de menores derivan hacia unos efectos y traumas posteriores en la edad adulta que serán muy complicados de erradicar y que pueden convertirse en problemas crónicos si no se plantean soluciones desde instancias jurídicas, educativas y de cualquier otra índole que actúen con rapidez y solvencia en contrarrestar esas circunstancias negativas tan perniciosas.

Por todo ello, y a pesar que existen normas internacionales, en particular en el seno de la Organización de Naciones Unidas y la Organización Mundial del Turismo, sí se hace necesario un gran acuerdo internacional que implique una mayor efectividad para la prevención y solución de este tipo de prácticas delictivas contra menores en los destinos turísticos.

Una segunda conclusión conectada con la anterior es preguntarse acerca si es posible delimitar, de manera cualitativa y cuantitativa, aquellos derechos fundamentales de la persona que se pueden encontrar más perjudicados cuando se es objeto de explotación sexual en los destinos turísticos tan anunciados en soportes telemáticos de última generación. Aunque la dignidad y el libre desarrollo de la personalidad, como derechos de la persona recogidos en el artículo 10 de la $\mathrm{CE}$, no se encuentren dentro del conjunto de derechos fundamentales y libertades públicas que gozan de una mayor protección jurídica en el ordenamiento jurídico español a través de la posible interposición de un recurso de amparo para invocar su reconocimiento ante el Tribunal Constitucional, es indudable que las connotaciones jurídicas que implican tienen importantes efectos si se hace presente su relevancia para hacer valer algunos derechos fundamentales como, por ejemplo, la defensa de la integridad física y moral del artículo 15 de la $\mathrm{CE}$ que, en numerosas ocasiones, es lo primero que subyace en las circunstancias de explotación de menores en el turismo sexual, y en particular, en todos los recursos técnicos que se utilizan para atraer la atención de visitantes con el objetivo que se conviertan en clientela potencial de las organizaciones que trafican con seres humanos con una finalidad de alto lucro económico.

En tercera y última instancia, uno de los efectos jurídicos que más sobresale cuando se repasa la función que desempeñan las nuevas tecnologías de la información y comunicación en todos aquellos acontecimientos negativos que rodean el mundo del turismo, y en especial, cuando se trata de la explotación sexual de menores por 
las organizaciones que han hecho de ello su objeto de comercio y transacción, es la posibilidad de amplificar sus consecuencias hacia unos límites que, hasta épocas no muy alejadas de la realidad actual, es muy probable que fueran ignoradas por los cuerpos judiciales y policiales de la mayor parte de los países desarrollados y, por extensión, del resto del mundo.

Es tanto el perjuicio que un inadecuado y mal uso de la tecnología provoca en las vidas de niñas y niños que, incluso, no se pueda cuando se escriben estas líneas pensar en las implicaciones finales que todo ello puede suponer. Los dispositivos tecnológicos, con independencia del soporte físico sobre el que se fundamenten, tienen una doble naturaleza permanente, en cuanto a los beneficios y las bondades que para la vida del ser humano conlleva una buena utilización de todos los aparatos que continuamente salen al mercado por parte de las multinacionales de la electrónica de consumo y la informática, pero, a la vez, las consecuencias tan negativas que pueden acarrear para la vida de niñas y niños cuando se realiza un abuso o mal empleo de esos recursos tecnológicos que contemplan innovaciones muy novedosas en la transmisión de datos, imágenes y sonidos por terceras personas que atentan contra los derechos fundamentales de menores.

\section{BIBLIOGRAFÍA}

ÁLVAREZ CONDE, E.: «Algunos aspectos del régimen jurídico de la prensa», Revista de derecho político, 34, 1991, pp. 11-70.

ÁLVAREZ CONDE, E.:»El sistema constitucional español de derechos fundamentales», Corts: Anuario de derecho parlamentario, (Ejemplar dedicado a: XXV aniversario de la Constitución Española), 15, 2004, pp. 115-146.

ARAGÓN REYES, M.: «Encuesta sobre la orientación actual del derecho Constitucional», Teoría y Realidad Constitucional, 1, 1998, p. 29.

ASENSI SABATER, J.: «Recensiones». En López Pina, A.; Gutiérrez Gutiérrez, I., Elementos de derecho público, Madrid, Marcial Pons, 2002, pp. 532-537.

BATISTA JIMÉNEZ, F.: «La dignidad de la persona en la Constitución española: naturaleza jurídica y funciones», Cuestiones Constitucionales, 14, 2006, pp. 3-20. 
BENDA, E.: «Dignidad humana y derechos de la personalidad». En BENDA, E.; MAIHOFER, W.; VOGEL, H.; HESSE, K.; HEYDE, H.: Manual de Derecho Constitucional, Madrid, Marcial Pons, 2001, pp. 117-144.

CAYETANO NÚÑEZ RIVERO, J. M.: «VERA SANTOS, José Manuel: Las Constituciones de España», Teoría y realidad constitucional, 25, 2010, pp. 695-702.

CLAVERO, B.: «Apunte para la ubicación de la Constitución de Bolivia», Revista Española de Derecho Constitucional, 89, 2010, pp. 195-217.

DE AGAPITO SERRANO, R.: «La Unión Europea y la globalización», Revista de derecho constitucional europeo, 12, 2009, pp. 101-114.

DE OTTO Y PARDO, I.: Derecho Constitucional. Sistema de Fuentes, Barcelona, Ariel, 2008.

DE VEGA GARCÍA, P.: «El tránsito del positivismo jurídico al positivismo jurisprudencial en la doctrina constitucional», Teoría y Realidad Constitucional, 1, 1998, pp. 65-87.

FERNÁNDEZ DE CASADEVANTE ROMANÍ, C.; JIMÉNEZ GARCÍA, F.: El Derecho Internacional de los Derechos Humanos en la Constitución Española: 25 años de jurisprudencia constitucional. Cizur Menor, Navarra, Aranzadi, 2006.

FERRAJOLI, L.: Derechos y garantías: la ley del más débil, Madrid, Trotta, 2004.

FERRANDO BADÍA, J.: Estudios de Ciencia Política, Madrid, Tecnos, 1992.

GAMBINO, S.: «El derecho constitucional común europeo entre teoría constitucional y praxis», Cuadernos de Derecho Público, 24. 2005, pp. 111-132.

GARCÍA BELAUNDE, D.: «Doctrina constitucional peruana en el siglo XX», Historia constitucional: Revista Electrónica de Historia Constitucional, 11, 2012, pp. 507-511.

GARCÍA COUSO, S; ÁLVAREZ CONDE, E.: «La barrera electoral», Revista de derecho político, 52, 2001, pp. 177-204.

GARCÍA GARCÍA, C.: El derecho a la intimidad y dignidad en la doctrina del Tribunal Constitucional, Murcia, Universidad de Murcia, Servicio de Publicaciones, 2003. 
GUILLÉN LÓPEZ, E.: «Metodología del Derecho Constitucional Europeo. Un derecho Constitucional para la integración política de Europa. Del pluralismo ideológico», Revista de derecho constitucional europeo, 12, 2009, pp. 151-170.

HÄBERLE, P.: «El estado constitucional europeo», Cuestiones constitucionales: revista mexicana de derecho constitucional, 2, 2000, pp. 87-104.

HOYOS, I.M.: «El respeto a la dignidad de la persona y los Derechos Humanos en la Constitución política de Colombia», Díkaion: revista de actualidad jurídica, 3, 1994, pp. 26-51.

JAKAB, A.: «Dos paradigmas encontrados del pensamiento constitucional en Europa: Austria y Alemania», Revista Española de Derecho Constitucional, 88, 2010, pp. 131-162.

LANDA, C.: «Dignidad de la persona humana», Cuestiones constitucionales: revista mexicana de derecho constitucional, 7, 2002, pp. 110-138.

LEGARRE, S.; ORREGO, C, «Los usos del derecho constitucional comparado y la universalidad de los derechos humanos», Revista Española de Derecho Constitucional, 88, 2010, pp. 11-38.

LÓPEZ GUERRA, L.: «Encuesta sobre la orientación actual del Derecho Constitucional», Teoría y Realidad Constitucional, 1, 1998, pp. 43-44.

MIRKINE-GUETZÉVITCH, B.: Derecho Constitucional Internacional, Madrid, Reus, 2008.

NUEVO, P.: «Pluralismo y bien común en el Derecho Constitucional囚, Díkaion: revista de actualidad jurídica, 13, 2004.

NÚÑEZ RIVERO, C.; GOIG MARTÍNEZ, J. M.; NÚÑEZ MARTÍNEZ, M.: Teoría del Estado Constitucional, Madrid, Universitas, 2010.

OEHLING DE LOS REYES, A.: «El concepto constitucional de dignidad de la persona: forma de comprensión y modelos predominantes de recepción en la Europa continental», Revista española de derecho constitucional, 31, 2011, pp. 135-178.

ROBLEDO, F. J.: «Las reformas constitucionales provinciales deben preservar el derecho a la dignidad de la persona humana en su integridad psicofísica», Estudios constitucionales: Revista del Centro de Estudios Constitucionales, 1, 2008, pp. 265-279. 
SAIZ ARNAIZ, A.: La apertura constitucional al Derecho Internacional y europeo de los derechos humanos. El artículo 10.2 de la Constitución Española, Madrid, Consejo General del Poder Judicial, 1999.

SÁNCHEZ BARRILAO, J. F.: «El derecho europeo y globalización: mitos y retos en la construcción del Derecho Constitucional Europeo囚, Revista de derecho constitucional europeo, 12, 2009, pp. 115-150.

SEEGER, J.: Atlas del estado de la mujer en el mundo, Madrid, Akal, 2001.

SERNA, P.: «La dignidad de la persona como principio de Derecho Público", Derechos y Libertades: revista del Instituto Bartolomé de las Casas, II (4), 1995, pp. 287-306.

TORRES DEL MORAL, A.: «Valores y principios constitucionales», Revista de derecho político, 36, 1992, pp. 17-26.

VERA SANTOS, J.M.: Las Constituciones de España, Navarra, ThomSon-Civitas, 2008.

VERA SANTOS, J.M.; CERVELLÓ GARCÍA, G.; RÍOS INSUA, D.: «E-democracia-cm y iparticipa Móstoles! promoción de la participación ciudadana con las TIC». En Ponencias del Congreso Tecnimap 2006, Sevilla, 30 de mayo a 2 de junio, 2006, pp. 1-6. 
